\title{
O Professor que Ensina Matemática e a sua Formação: uma experiência em Portugal
}

\author{
Maria de Lurdes Serrazina' \\ 'Instituto Politécnico de Lisboa (IPL), Lisboa - Portugal
}

\begin{abstract}
RESUMO - O Professor que Ensina Matemática e a sua Formação: uma experiência em Portugal. Este artigo discute características da formação continuada de professores polivalentes em Matemática, que podem conduzir a alterações na sua relação com a Matemática e nas suas práticas de sala de aula. Para isso retoma o Programa de Formação Contínua em Matemática (PFCM), desenvolvido em Portugal. Discute o conhecimento do professor para ensinar Matemática, tipos de conhecimento necessários para um ensino proficiente e relaciona-os com o desenvolvimento de uma atitude de confiança do professor como professor que ensina Matemática. Apresenta, o caso de uma professora, formanda do PFCM durante dois anos, evidenciando o contributo do Programa para o desenvolvimento do seu conhecimento e da sua postura como professora que ensina Matemática.

Palavras-chave: Conhecimento do Professor. Confiança. Ensino Proficiente. Formação Continuada.
\end{abstract}

ABSTRACT - The Teacher who Teaches Mathematics and their Education: an experience in Portugal. This paper discusses the characteristics of continuing education for polyvalent teachers in mathematics, which may lead to changes in their attitude towards mathematics and their classroom practices. It approaches the Continuous Education Program in Mathematics (PFCM), developed in Portugal. It discusses the knowledge of the teacher to teach mathematics, the types of knowledge required for a proficient teaching, and relates them to the development of a confidence attitude in the teacher as the one who teaches mathematics. It presents the case of a teacher, trainee of PFCM for two years, highlighting the contribution of the program for the development of her knowledge and position as a teacher who teaches mathematics. Keywords: Teacher Knowledge. Confidence. Proficient Education. Continuing Education.

Educação \& Realidade, Porto Alegre, v. 39, n. 4, p. 1051-1069, out./dez. 2014.

1051

Disponível em: <http://www.ufrgs.br/edu_realidade> 


\section{Introdução}

Ser professor de Matemática no século XXI implica enfrentar diariamente múltiplos desafios. Ser professor que ensina matemática nos anos iniciais da escolaridade coloca questões ainda mais complexas que se prendem com o ensinar e aprender nestas idades, com a formação dos professores nas diferentes áreas do saber e em particular na Matemática e com o que pode ser considerado um professor proficiente para trabalhar com esta faixa etária. Conscientes desta situação desenvolveu-se em Portugal, por iniciativa do Ministério de Educação, um Programa de Formação Contínua em Matemática (PFCM) para os professores do $1 .^{\circ}$ ciclo do ensino básico ( $1 .^{\circ}$ ao $4 .^{\circ}$ ano de escolaridade) durante seis anos letivos.

Neste artigo discute-se o conhecimento do professor, a importância da autoconfiança e a relação entre conhecimento e confiança de modo a que o professor possa realizar aquilo que Kilpatrick, Swafford e Findell (2001) designam por ensino proficiente. Apresenta-se depois resumidamente o PFCM, os seus objetivos, princípios e organização. $\mathrm{O}$ artigo prossegue com o caso da professora Maria, formanda do PFCM durante dois anos, integrada num grupo de formação no qual a autora deste artigo era formadora. A concluir, discute-se um conjunto de características de um programa de formação continuada para professores polivalentes capaz de produzir alterações na relação dos professores com a Matemática e o seu ensino e nas suas práticas de sala de aula.

\section{Conhecimento do Professor para Ensinar Matemática}

A ideia de que só se pode ensinar o que se sabe tem vindo a ser discutida entre os educadores matemáticos, designadamente a partir dos trabalhos de Shulman. Este autor ao definir Conhecimento do Conteúdo Pedagógico (Pedagogical content knowledge, PCK) deu especial ênfase "[...] às mais úteis formas de representação [...] as mais poderosas analogias, ilustrações, exemplos, explicações e demonstrações - numa palavra, as formas de representar e formular a disciplina que a torna compreensível aos outros" (Shulman, 1986, p. 9). Ball, Thames e Phelps (2005), interpretando e desenvolvendo as ideias de Shulman, apresentam um modelo para descrever o conhecimento matemático para ensinar incluindo o conhecimento de ensino da matemática como: (1) conhecimento do conteúdo e dos alunos, isto é, conhecimento associado ao facto de os professores terem de antecipar possíveis erros e conceções erradas dos alunos, interpretar os seus pensamentos incompletos e prever o que é provável que os alunos façam perante tarefas específicas e o que para eles será interessante ou desafiante; (2) conhecimento do conteúdo e do ensino, isto é, o conhecimento associado à necessidade de os professores sequenciarem os conteúdos a ensinar, reconhecerem os prós e contras de representações difíceis e irem adaptando as questões matemáticas para responderem a novas abordagens dos alunos.

1052 Educação \& Realidade, Porto Alegre, v. 39, n. 4, p. 1051-1069, out./dez. 2014. Disponível em: <http://www.ufrgs.br/edu_realidade> 
Posteriormente os mesmos autores (Ball; Thames; Phelps, 2008) consideraram o conhecimento pedagógico de conteúdo como uma espécie de amálgama de conhecimento de conteúdo e de pedagogia central ao conhecimento necessário para ensinar e a compreensão do professor de como ajudar os alunos a compreender assuntos específicos. Estes autores descreveram o conhecimento matemático necessário para ensinar como aquele indispensável para levar a cabo o trabalho de ensinar matemática e que envolve, entre outros aspetos, a compreensão do conteúdo do currículo com vista a ser capaz de ajudar os alunos, responder às suas questões, planear a sua aprendizagem e avaliar o seu trabalho. Aqueles autores consideraram: (i) por um lado o conhecimento matemático do conteúdo, que abarca o conhecimento comum do conteúdo, algo que o cidadão comum deve possuir, e o conhecimento especializado do conteúdo, sendo este último àquele que se considera indispensável para exercer a função de professor e que, no caso da Matemática, inclui uma perspetiva sobre a natureza da matemática e um conhecimento aprofundado daquilo que o professor tem de ensinar aos seus alunos; (ii) por outro o conhecimento pedagógico do conteúdo englobando o conhecimento do conteúdo e dos alunos, e o conhecimento do conteúdo e do ensino, na perspetiva que o ensino eficaz envolve saber o que os alunos sabem e não sabem, o que eles necessitam saber e como ajudá-los a progredir nesse saber.

Também Fiorentini, Nacarato e Pinto (1999), procurando sintetizar o que designam por saber docente, afirmam que este pode ser concebido,

\begin{abstract}
[...] como um saber reflexivo, plural e complexo porque histórico, provisório, contextual, formando uma teia, mais ou menos coerente e imbricada, de saberes científicos - oriundos das ciências da educação, dos saberes das disciplinas, dos currículos - e de saberes da experiência e da tradição pedagógica (Fiorentini; Nacarato; Pinto, 1999, p. 55).
\end{abstract}

Enquanto que Kilpatrick, Swafford e Findell (2001), focando o professor de Matemática, discutem o que é ser proficiente no ensino da matemática, considerando que se os professores querem desenvolver proficiência matemática nos seus alunos, devem ter uma visão clara dos objetivos de ensino e o que significa proficiência nos conteúdos matemáticos que estão a ensinar. Definem como cruciais para ensinar matemática três tipos de conhecimento:

(1) Conhecimento da matemática, que inclui conhecimento dos factos, dos conceitos e dos procedimentos e das relações entre eles; conhecimento da forma como as ideias matemáticas podem ser representadas; e conhecimento da matemática como uma disciplina - em particular como o conhecimento matemático é produzido, a natureza do discurso em matemática, mas também conhecer os objetivos do ensino da matemática e ser capaz de discriminar e priorizar esses objetivos.

Educação \& Realidade, Porto Alegre, v. 39, n. 4, p. 1051-1069, out./dez. 2014.1053 Disponível em: <http://www.ufrgs.br/edu_realidade> 
Conhecimento da matemática para ensinar é mais do que saber matemático para si próprio, é compreender corretamente conceitos, bem como realizar procedimentos, mas também ser capaz de compreender os fundamentos concetuais desses conceitos e procedimentos. Estes autores referem ser pouco provável que os professores consigam proporcionar aos seus alunos uma boa explicação de conceitos que eles não compreendem e mais dificilmente serão capazes de envolver os seus alunos em discussões produtivas sobre as múltiplas formas de resolver um dado problema, se eles próprios só o conseguem resolver de uma única forma. A compreensão que têm da matemática deve-lhes permitir, no seu trabalho como professores, explicar e desempacotar (unpack) ideias de um modo que não é necessário ao cidadão adulto comum.

(2) Conhecimento dos alunos e de como eles aprendem matemática e conhecimento das práticas de ensino, incluindo conhecimento geral de como as várias ideias matemáticas se desenvolvem nas crianças ao longo do tempo, assim como o conhecimento específico para determinar onde, numa trajetória de desenvolvimento, uma criança pode estar. Este conhecimento compreende ainda o estar familiarizado com dificuldades comuns que os alunos têm com certos conceitos e procedimentos englobando conhecimentos sobre aprendizagem e sobre tipos de experiências, conhecer outras abordagens que influenciam o pensamento e a aprendizagem dos alunos.

(3) Conhecimento das práticas de ensino, inclui o conhecimento do currículo, conhecimento das tarefas e ferramentas para ensinar importantes ideias matemáticas, conhecimento de como conceber e gerir o discurso na aula e conhecimento de normas de sala de aula que apoiam o desenvolvimento da proficiência matemática. Mas, a forma como os professores interpretam e implementam o currículo é condicionada pelo conhecimento e crenças do professor, a sua identidade profissional, contextos organizacionais e políticos e as normas e estrutura de sala de aula (Stein; Remillard; Smith, 2007). Por sua vez, o tipo de tarefas que o professor propõe aos alunos influencia a forma como estes aprendem a pensar matematicamente (Stein; Smith, 1998). A leitura que os professores fazem do currículo é concretizada nas suas práticas de sala de aula, pondo em ação o seu conhecimento curricular e a forma como articulam verticalmente e horizontalmente os conteúdos matemáticos, o conhecimento e a utilização de materiais manipuláveis, de tecnologias e de outros recursos.

Assim, a formação continuada deve contribuir para que os professores avancem no nível de compreensão das suas práticas. A reflexão, como definida por Schon (1983), entendida como a reflexão na ação, quando feita no decurso da própria ação, sem a interromper, mas com breves instantes de distanciamento e de possível reformulação dessa ação; a reflexão sobre a ação quando esta é reconstruída retrospetivamente para analisá-la; e a reflexão sobre a reflexão na ação (meta-re-

1054 Educação \& Realidade, Porto Alegre, v. 39, n. 4, p. 1051-1069, out./dez. 2014. Disponível em: <http://www.ufrgs.br/edu_realidade> 
flexão), processo que leva o profissional a progredir no seu desenvolvimento e a construir o seu conhecimento (Alarcão, 1996), é essencial. O objeto de reflexão é tudo o que se relaciona com a atuação do professor durante $o$ ato educativo como, contexto, métodos, finalidades de ensino, conhecimentos e capacidades que os alunos estão a desenvolver, dificuldades surgidas, conhecimentos e fragilidades do professor, etc. Neste sentido, a reflexão joga um papel central no desenvolvimento profissional dos professores (Serrazina, 1999). Acredito como Jaworski (1993) que a reflexão provoca a ação, na medida em que quando refletem os professores tornam-se mais confiantes na sua capacidade para lidar com a Matemática de modo diferente, identificando as suas fragilidades, mas também as suas potencialidades. Ao mesmo tempo sentem a necessidade de saber mais matemática para poderem propor tarefas diferentes na sala de aula e envolver os alunos em diferente atividade matemática. Neste processo, é esperado que ocorram novos saberes docentes e novos sentidos para a sua prática letiva (Curi, 2005; Fiorentini; Nacarato; Pinto, 1999).

\section{Conhecimento e Confiança}

Sendo o conhecimento do professor um aspeto fundamental da sua formação esta tem também de promover uma atitude positiva perante a Matemática e o seu ensino, indispensável ao desenvolvimento da confiança para aprender e ensinar Matemática (Curi, 2005; Serrazina, 1999).

Diferentes estudos mostram que há uma relação positiva entre a confiança dos professores e a melhoria do seu conhecimento matemático (Beswick; Ashman; Callingham; McBain, 2011; Serrazina, 1999). Parece, pois, existir uma estreita relação entre a melhoria do conhecimento matemático, que conduz a um melhor ensino, o que, por sua vez, leva à necessidade de saber mais matemática e didática e ao desenvolvimento da confiança. Também Graven (2004) conclui que a confiança dos professores parece crescer à medida que vai crescendo o seu domínio de novas ideias e práticas.

Especificamente, Graven sugere que,

$$
\begin{aligned}
& \text { [...] confiança [é] quer produto (resultado da aprendi- } \\
& \text { zagem do professor) quer processo (uma explicação da } \\
& \text { aprendizagem do professor) e esta envolve [...] confiança } \\
& \text { na sua capacidade de aceder a recursos para complemen- } \\
& \text { tar a sua aprendizagem [e] confiança na sua identidade } \\
& \text { profissional como educador matemático competente } \\
& \text { (Graven, 2004, p. 206). }
\end{aligned}
$$

Esta confiança também se manifesta na expetativa que o professor tem relativamente ao que os seus alunos são capazes de aprender em Matemática (Curi, 2005; Serrazina, 1999).

Educação \& Realidade, Porto Alegre, v. 39, n. 4, p. 1051-1069, out./dez. 2014.1055 Disponível em: <http://www.ufrgs.br/edu_realidade> 
É na sala de aula que se manifestam não apenas o conhecimento do professor, mas também as suas conceções sobre a Matemática e o seu ensino, bem como o seu nível de confiança como professor que ensina Matemática. Daí que a formação como desenvolvimento profissional tenha que ter em consideração as práticas de sala de aula para que sejam problematizadas e objeto de reflexão (Nacarato; Mengali; Passos, 2009). Uma formação dirigida ao questionamento e problematização das práticas exige tempo, como é referido por Curi e Pires (2008), num artigo em que passam em revista várias pesquisas realizadas no Brasil, no âmbito da formação continuada, concluindo que "[...] muitas vezes o tempo de formação é insuficiente, tanto para que o professor se aproprie de conhecimentos que não domina, como para que ele ganhe confiança e disposição para realizar mudanças em sua prática" (Curi; Pires, 2008 , p. 183). Concluem também que as possibilidades de apropriação de conhecimentos matemáticos, didáticos e curriculares melhoram "[...] quando professores participam de processos de formação continuada que possibilitam reflexões, relações entre teoria, prática e pesquisa e o tratamento articulado das diferentes vertentes do conhecimento do professor" (Curi; Pires, 2008, p. 183).

Para que o professor possa refletir sobre a sua prática, a planificação da atividade letiva é um aspecto importante. No entanto, mesmo quando os professores fazem boas planificações, incluindo nelas possíveis resoluções e atitudes dos alunos, quando as concretizam, na sala de aula, enfrentam diariamente novos desafios. Embora não exista uma solução ideal, os professores podem aprender a lidar com os possíveis problemas que vão surgindo na sala de aula, tendo em conta a matemática que os alunos estão a aprender, o que eles já compreendem e as representações, atividades e práticas de ensino que já se sabe funcionam melhor e que têm sido eficazes na aprendizagem de determinados tópicos. Todos estes aspetos podem ser equacionados na planificação e objeto de reflexão no pós-aula.

Deste modo, os professores podem aprender a partir do seu ensino analisando-o, em especial as dificuldades que os seus alunos enfrentam na aprendizagem de determinado tópico, o que aprenderam, como responderam a representações, questões e tarefas particulares. Escutando os alunos, os professores não apenas desenvolvem conceções mais elaboradas de como se desenvolve o seu pensamento matemático, mas neste processo interativo vão desenvolvendo estratégias e aprendendo a lidar com os conceitos matemáticos que querem ensinar-lhes. A reflexão sobre a prática pode focar-se em aspetos como: que matemática ensinar, que objetivos atingir pelos alunos, nas conceções e nas conceções erradas que os alunos têm sobre a matemática, as dificuldades que têm na sua aprendizagem e as representações que são mais eficazes na comunicação de ideias matemáticas essenciais.

Assim, os professores tornam-se mais confortáveis com as ideias matemáticas, mais confiantes como professores de matemática e ad-

1056 Educação \& Realidade, Porto Alegre, v. 39, n. 4, p. 1051-1069, out./dez. 2014 Disponível em: <http://www.ufrgs.br/edu_realidade> 
quirem uma visão mais sistemática da disciplina, desenvolvendo-se profissionalmente. Este desenvolvimento é potenciado quando os professores compartilham o seu trabalho num ambiente colaborativo (Nacarato; Mengali; Passos, 2009).

Os pressupostos teóricos enunciados anteriormente estiveram na base da definição, organização e implementação do Programa de Formação Contínua em Portugal, dirigido a professores do $1^{\circ}$ ciclo que ensinam Matemática.

\section{O Programa de Formação Contínua em Matemática}

O Programa de Formação Contínua em Matemática (PFCM) desenvolveu-se em Portugal entre 2005 e 2011 e destinou-se a professores do $1^{\circ}$ ciclo do ensino básico ${ }^{1}$. O PFCM foi uma iniciativa do Ministério da Educação e envolveu as instituições de ensino superior (IES) públicas que, à data, estavam envolvidas na formação inicial de professores daquele nível de ensino - 18 IES em Portugal continental. O programa foi monitorizado em termos científico-pedagógicos por uma Comissão de Acompanhamento, também responsável pela elaboração das suas linhas programáticas (Serrazina; Canavarro; Guerreiro; Rocha; Portela; Saramago, 2005). Cada IES indicou um coordenador, responsável pela organização e coordenação de uma equipa local de formadores. Estes eram docentes de Matemática ou de Didática de Matemática da instituição e professores de outros níveis de ensino, com um perfil adequado, que incluia um conhecimento aprofundado da sala de aula do $1^{\circ}$ ciclo do ensino básico.

Foram definidos como objetivos do PFCM: (i) Aprofundar o conhecimento matemático, didático e curricular dos professores envolvidos; (ii) Favorecer a realização de experiências de desenvolvimento curricular em Matemática que contemplassem a planificação de aulas, a sua condução e reflexão por parte dos professores envolvidos, apoiados pelos seus pares e formadores; (iii) Fomentar uma atitude positiva dos professores relativamente à Matemática, promovendo a autoconfiança nas suas capacidades como professores de Matemática, incluindo a criação de expetativas elevadas acerca do que os seus alunos podem aprender em Matemática; (iv) Criar dinâmicas de trabalho em colaboração entre os professores de cada escola e também de cada agrupamento de escolas com vista a um investimento continuado no ensino da Matemática ao nível do grupo de professores da escola/agrupamento (DR, Despacho conjunto 812/2005).

No PFCM entendeu-se por conhecimento matemático do professor o conhecimento e compreensão aprofundada da matemática que ensinam (Ball, 1991), encarado como um conhecimento especializado que envolve a compreensão das explanações e métodos não convencionais de resolução de problemas pelos alunos e a construção e avaliação de

Educação \& Realidade, Porto Alegre, v. 39, n. 4, p. 1051-1069, out./dez. 2014.1057 Disponível em: <http://www.ufrgs.br/edu_realidade> 
múltiplas representações de conceitos matemáticos. Como já referido, o professor precisa desempacotar a Matemática, isto é, não pode limitar-se às definições e conceitos matemáticos acabados, mas tem de desdobrá-los de modo que os alunos vão construindo esses conceitos com compreensão. Assim, saber matemática para ensinar exige uma profundidade e detalhe que vai muito para além de saber fazer bem um procedimento (Ball; Bass, 2003).

Já o conhecimento didático, a adequação do conhecimento matemático ao ensino, concretiza-se através da construção e seleção de tarefas e de materiais para a sala de aula, da forma como se faz a organização e gestão da aula, o conhecimento sobre a aprendizagem e os alunos e ainda a forma de estabelecer a comunicação e negociação de significados matemáticos com os alunos e entre eles.

Para além dos objetivos do PFCM mencionados anteriormente, foram definidos um conjunto de princípios subjacentes ao seu desenvolvimento (Serrazina; Canavarro; Guerreiro; Rocha; Portela; Saramago, 2005), de que destaco: (i) Valorização do desenvolvimento profissional do professor, considerando que este possui um conhecimento profissional específico, multifacetado, que desenvolve continuadamente ao longo do tempo, em diálogo com as experiências diversas que vai vivendo, nomeadamente no contexto concreto das escolas em que leciona e com as turmas que vai encontrando; (ii) Valorização de uma formação matemática de qualidade para o professor, tendo em conta que este deve possuir um conhecimento matemático de qualidade, articulado com o conhecimento curricular e didático específico, bem como um conhecimento sobre os processos de aprendizagem dos alunos, sendo capaz de identificar e reconhecer as suas dificuldades, respetivas origens, e de aproveitar o erro como fonte de aprendizagem; (iii) Valorização do desenvolvimento curricular em Matemática, que inclui proporcionar aos alunos experiências matemáticas significativas sendo essencial o investimento intencional numa preparação/planificação e lecionação cuidadas, orientada por uma visão integrada das várias componentes curriculares (objetivos, conteúdos, tarefas, métodos de trabalho e avaliação), que contemple a reflexão sobre as implicações nas aprendizagens - ou seja, uma prática continuada de desenvolvimento curricular; (iv) Reconhecimento das práticas letivas dos professores como ponto de partida da formação; (v) Consideração das necessidades concretas dos professores relativamente às suas práticas curriculares em Matemática, pois cada professor deve conhecer as suas potencialidades e fragilidades, e ser capaz de diagnosticar as suas prioridades no domínio da formação; (vi) Valorização do trabalho colaborativo entre diferentes atores, dado que a dimensão coletiva do trabalho dos professores é extremamente importante pelas mais-valia que permite obter.

Tendo em conta os objetivos e princípios enunciados, foi decidido que a formação fosse continuada no tempo e implicasse diretamente a prática na sala de aula. A ideia de introduzir uma componente de sala 
de aula resultou ainda de, por um lado, a percepção de que muita da formação realizada, em Portugal até aí, não tinha tido repercussão na sala de aula e por outro o relatório do PISA 2003 (OCDE, 2004) afirmar que apenas $6 \%$ dos alunos portugueses testados tiveram alguma vez as suas aulas acompanhadas por outro professor mais experiente, quando na média dos países participantes aquela percentagem era de $61 \%$. Foi, pois, estabelecido que a formação contemplasse essencialmente dois tipos de sessões:

1) Sessões de formação em grupo em horário não letivo, para exploração e aprofundamento do conhecimento matemático e didático relativo a temas curriculares, com planificação de sequências coerentes de aulas e reflexão sobre essas aulas. Assim estas sessões, que decorriam cada duas semanas, organizaram-se, de um modo geral, em três momentos: um onde era feita a reflexão do que mais relevante tinha acontecido nas aulas acompanhadas após a última sessão, outro onde era trabalhado um tópico matemático e um terceiro onde era iniciada a planificação das aulas seguintes. Estas planificações eram posteriormente acompanhadas pelo formador, muitas vezes à distância, através de mensagens de correio eletrónico, em especial com cada um dos professores cujas aulas seriam objeto de acompanhamento no período seguinte.

2) Sessões de acompanhamento/supervisão na sala de aula pelo formador, entendendo a supervisão como uma "[...] atuação de monitorização sistemática da prática pedagógica, sobretudo através de procedimentos de reflexão e experimentação" (Vieira, 1993, p. 38) incluindo supervisionar processos de observação, reflexão e ação do e com o professor. Com estas sessões era garantida a presença efetiva do formador em aulas de cada professor ao longo do ano letivo, para o desenvolvimento de atividades curriculares, correspondentes à condução das práticas que concretizavam a planificação trabalhada nas sessões de formação em grupo e respetiva discussão. Estas sessões de acompanhamento da prática letiva eram dirigidas ao apoio individual de cada professor, tiveram alguma oscilação, em termos de número, ao longo dos anos (variaram entre três e cinco) sendo a média de quatro por ano letivo e por professor.

Considerando os objetivos de formação e a necessidade de concretizar uma relação estreita entre a sala de aula e as sessões de formação em grupo baseada na reflexão sobre a implementação das tarefas, foi acordado, desde início, que os grupos tinham de ter um número reduzido de participantes. Assim, foi determinado que os grupos tivessem entre 8 e 12 formandos em 2005/06, tendo posteriormente esse número sido fixado entre 8 e 10 formandos. Este número permitia que o formador pudesse estar num número mínimo de aulas de cada formando ao longo do ano letivo e que as sessões de formação em grupo se desenvolvessem num ambiente favorável para a discussão e reflexão conjunta.

Educação \& Realidade, Porto Alegre, v. 39, n. 4, p. 1051-1069, out./dez. 2014.1059 Disponível em: <http://www.ufrgs.br/edu_realidade> 
Constituiu ainda parte integrante da formação, desde o seu início, a realização de um seminário final de um dia (6 horas), onde participavam todos os professores envolvidos na formação ao longo do ano lectivo e, em muitas IES, abertos à comunidade educativa. Tratava-se de um momento de partilha e reflexão sobre a experiência formativa realizada.

Os professores em formação tinham ainda de elaborar, ao longo do ano letivo, um portefólio reflexivo, onde obrigatoriamente incluíam planificações de aulas, reflexões sobre as mesmas e análises e reflexões das produções dos alunos em pelo menos duas tarefas, desenvolvidas em aulas acompanhadas. A elaboração do portefólio era acompanhada pelo formador, desejavelmente ao longo do ano letivo. À medida que o formando selecionava os elementos a incluir no portefólio, enviava-os ao formador que lhe devolvia o seu feedback sobre o mesmo. Este processo não foi fácil de gerir, quer por formandos quer por formadores, tratava-se de um processo complexo, que obrigatoriamente deveria conter: análises das resoluções dos alunos, do ponto de vista da matemática nela contida, mas também a aprendizagem realizada e ainda uma reflexão escrita sobre a aula e sobre o processo formativo vivido. Inicialmente a existência do portefólio teve alguma resistência, em especial por exigir um registo escrito, mas gradualmente foi percecionada a sua utilidade e o seu contributo para o desenvolvimento profissional, como mostram pesquisas desenvolvidas no seio do PFCM (por exemplo, Martins, 2011). Estas mostram que os portefólios revelaram trazer mais-valias para o desenvolvimento profissional dos professores, nomeadamente ao nível do aprofundamento da sua capacidade de reflexão.

A formação desenvolveu-se por ano letivo e teve caráter voluntário. Dado que os processos de desenvolvimento professional, como este em que os professores estavam envolvidos, são naturalmente lentos foi aberta a possibilidade de os professores que assim o entendessem poderem candidatar-se à frequência de dois anos de formação (seguidos ou interpolados). O balanço que foi possível ir fazendo do PFCM mostra a sua mais-valia para os professores que nele participaram durante dois anos:

[...] é visível, testemunhada um pouco por todo o país, uma attitude professional de maior empenhamento e investimento no ensino da Matemática, com maior consciência nos desafios que se colocam e com maior capacidade de lhes fazer face - maior sensibilidade para os problemas da aprendizagem da Matemática, maior conhecimento da Matemática a ensinar e como o fazer, maior predisposição para planificar de forma cuidadosa e aprofundada a aula de Matemática e um maior conhecimento dos recursos a mobilizar (Serrazina, 2009, p. 21).

1060 Educação \& Realidade, Porto Alegre, v. 39, n. 4, p. 1051-1069, out./dez. 2014 Disponível em: <http://www.ufrgs.br/edu_realidade> 
Apresenta-se de seguida o caso da professora, Maria, que participou no PFCM durante dois anos, identificando mais-valias dessa participação.

\section{O Caso da Professora Maria}

Para a construção deste caso foram utilizadas diversas fontes de dados, como, as notas da observação participante que fui realizando ao longo da formação, quer nas sessões de supervisão, quer nas sessões de formação em grupo, mas também, as notas de campo tomadas a seguir às sessões de supervisão das aulas da Maria e subsequente reflexão pós-aula, bem como a seguir às sessões de formação em grupo. Constituíram também fonte de dados os portefólios reflexivos elaborados por Maria, um por cada ano que participou na formação.

O foco da análise, que aqui se apresenta, é na formação e como ela contribuiu para o aprofundamento do conhecimento e influenciou o desenvolvimento da sua confiança como professora que ensina Matemática melhorando a sua prática letiva, essa análise, tem maior incidência no $2 .^{\circ}$ ano de formação, não descurando o $1 .^{\circ}$ ano. Todos os documentos foram lidos e relidos, procurando extrair ideias do que foi para Maria a participação nos dois anos no PFCM e porque o fez. Procurou-se, em especial, compreender como é que a formação influenciou o seu conhecimento profissional e o modo de ser professora de Matemática e identificar características da formação que o potenciaram.

Maria é professora do $10^{\circ}$ ciclo do ensino básico com uma larga experiência como professora (mais de 15 anos de serviço à data da formação). Frequentou o PFCM durante dois anos, integrada num grupo de que a autora era formadora, sendo a única professora da sua escola no grupo. Este facto, segundo Maria, deve-se ao reduzido número de professores a lecionar na sua escola e à falta de estabilidade professional de algumas das suas colegas.

Maria lecionava uma turma do $3 .^{\circ}$ ano, com 20 alunos, no primeiro ano que frequentou o PFCM, tendo continuado com a mesma turma, no $4 .^{\circ}$ ano, embora alguns alunos tenham sido transferidos e novos alunos se tenham integrado. Maria é uma professora, respeitada pelos colegas e pelos pais, quer na sua escola quer no seu agrupamento e muito preocupada com o seu desenvolvimento profissional. Trabalha há alguns anos na mesma escola localizada num bairro da periferia da cidade de Lisboa, frequentada por uma população da classe média baixa. Tem uma boa relação com os alunos a quem explicou a minha presença na sala de aula, apresentando-me como: a professora é professora de Matemática e é a minha professora de Matemática, pois agora também ando a estudar.

O grupo de professores que Maria integrou no $1^{\circ}$ ano de formação manteve-se parcialmente no $2 .^{\circ} \mathrm{ano}^{2}$, sendo constituído por 10 profes-

Educação \& Realidade, Porto Alegre, v. 39, n. 4, p. 1051-1069, out./dez. 2014.1061 Disponível em: <http://www.ufrgs.br/edu_realidade> 
sores, com diferentes experiências e a lecionar os diferentes anos de escolaridade do $1^{\circ}$ ciclo. No final do $1^{\circ}$ ano de formação, Maria e as colegas organizaram-se de modo a viabilizar a realização do PFCM pela segunda vez para o seu grupo de formação. Para isso garantiram a existência de um grupo e propuseram a sua continuidade à IES, que a conseguiu viabilizar. Na sua proposta o grupo referia à necessidade de trabalhar mais aprofundadamente alguns temas do currículo e, em especial a geometria.

\section{Percurso de Maria ao Longo da Formação}

No início do $1^{\circ}$ ano de formação, Maria justifica a sua participação pelas limitações que sabia ter em Matemática, pois tinha muitas dificuldades em propor tarefas aos seus alunos para além daquelas incluídas no livro didático. Procurava, sobretudo, novas abordagens e novos métodos para criar nos seus alunos o gosto pela Matemática.

Nas sessões de formação em grupo, Maria foi sempre uma formanda muito participativa levantando questões e dando a sua opinião muitas vezes inquiridora, questionando as colegas e a formadora.

Nas sessões de supervisão, começou por me apresentar aos seus alunos, na $1^{\text {a }}$ sessão de acompanhamento, como professora de Matemática, acrescentando que, poderiam pedir-me esclarecimentos e ela faria $o$ mesmo, o que veio a acontecer por diversas vezes.

Maria aproveitava as aulas supervisionadas para realizar as tarefas, analisadas e discutidas nas sessões de formação em grupo, em especial aquelas em que não se sentia ainda confiante para realizá-las sem apoio, normalmente tarefas exploratórias e de investigação (Ponte, 2005). No seu portefólio justifica esta situação pelo desejo de realizar as tarefas com os alunos e a segurança que sentia com a presença da formadora para responder a questões que surgissem da parte dos alunos.

Maria fazia uma planificação cuidada das aulas acompanhadas, antecipando possíveis resoluções dos alunos, mas também possíveis dificuldades, e elaborava os materiais de ensino a utilizar. Esta planificação era iniciada na sessão de formação, completada depois por Maria e previamente enviada à formadora, que a analisava e dava o seu feedback antes da aula acontecer e, sempre que se justificava, reformulada e enviada de novo.

Na sala de aula, Maria concretizava a planificação e sempre que não se sentia segura perante o questionamento dos alunos, dirigia-se diretamente à formadora. Isto aconteceu, por exemplo, no $1^{\circ}$ ano de formação quando introduziu o algoritimo da divisão, com um divisor de dois algarismos, do modo como tinha sido discutido no grupo de formação, utilizando factos básicos da multiplicação e subtrações sucessivas. Os alunos utilizaram diferentes estratégias, tendo Maria questionado: se todas iriam conduzir ao algoritmo simplificado? Na reflexão pós-aula

1062 Educação \& Realidade, Porto Alegre, v. 39, n. 4, p. 1051-1069, out./dez. 2014. Disponível em: <http://www.ufrgs.br/edu_realidade> 
analisámos a situação, discutindo possíveis estratégias, para que Maria se sentisse confortável na orientação do processo de aprendizagem de cada um dos alunos. Perante a reação muito positiva dos alunos e a rapidez com que avançaram, Maria ficou entusiasmada escrevendo na reflexão sobre esta aula, incluída no seu portefólio, do $1^{\circ}$ ano de formação:

Afinal os alunos compreenderam muito bem. Para este grupo foi muito mais fácil passarem a fazer contas de dividir que para os grupos que tive anteriormente. Mas para mim foi muito confortável a formadora estar lá no início, senti-me confiante, de outro modo não sei se teria avançado por ali.

Maria sentia-se insegura e receosa por temer não ter resposta para os eventuais caminhos seguidos pelos alunos. A presença da formadora deu-lhe a segurança para avançar, a reação favorável dos alunos foi fundamental no reforço da confiança e na continuidade do trabalho. A reflexão pós-aula com a formadora permitiu analisar os episódios ocorridos e esclarecer algumas dúvidas. Mais tarde o seu conhecimento foi enriquecido ao partilhar com o grupo das colegas da formação a sua experiência, ao explicitar as suas dúvidas e preocupações e ao ouvir as das colegas que também tinham desenvolvido o mesmo tipo de experiência nas suas aulas.

Sobre a sua decisão de frequentar o $2^{\circ}$ ano de formação pode ler-se no seu portefólio:

A minha motivação para prosseguir a formação de Matemática no $2^{\circ}$ ano emergiu da minha vontade [...] em adquirir mais conhecimento quer ao nível científico, quer ao nível pedagógico-didático.

Enumera depois outros motivos, nomeadamente o ambiente no grupo de formação, mas também a sua vontade de fazer um melhor ensino da Matemática, referindo:

Como docente, no que respeita à transmissão de conhecimentos, gostaria de fazê-lo [...] de uma forma fiel, mais interessante e até mais aliciante, de forma a desenvolver, nas crianças, o gosto pela Matemática.

O aprofundamento dos conhecimentos relativamente à Matemática e à sua didática pesou também na decisão de Maria para se inscrever pela segunda vez na formação. No seu portefólio final ela regista esta ideia do seguinte modo:

Não foi a busca ou a necessidade de créditos que me norteou, nem muito menos a falta de ocupação interessante, após um dia de aulas, ou o gosto em me deslocar, a toda a pressa, para outra escola, local da formação. [...] Espero com esta formação alargar e aprofundar conhecimentos que possam colmatar dúvidas, resolver problemas e contribuir para um maior sucesso dos alunos e assumir melhor qualidade no processo de ensino-aprendizagem.

No seu segundo ano de formação Maria continuou, como era sua intenção, a cimentar o seu conhecimento matemático e didático e a

Educação \& Realidade, Porto Alegre, v. 39, n. 4, p. 1051-1069, out./dez. 2014.1063 Disponível em: <http://www.ufrgs.br/edu_realidade> 
levar para a sala de aula tarefas que considerava interessantes e motivadoras para os seus alunos. Um dos tópicos tratados nas sessões de formação em grupo foi o das planificações de figuras tridimensionais, nomeadamente as diferentes planificações do cubo. Para Maria esta tarefa constituiu um desafio, pois nunca antes tinha sido confrontada com ela. Até ali as planificações do cubo eram as que vinham no livro didático, normalmente apenas uma. Exatamente por isso, Maria decidiu planificar a sua primeira aula supervisionada, do $2^{\circ}$ ano de formação, sobre este tópico, uma vez que a formadora estaria presente e poderia ajudar, caso fosse necessário. Utilizou materiais manipuláveis (polidrons, os mesmos que tinham sido utilizados por si na sessão de formação em grupo), devendo os alunos fazer depois o registo, numa ficha quadriculada (desenhada previamente por ela no computador e impressa), de cada uma das planificações que iam descobrindo. Como para a professora, também para os alunos foi a primeira vez que utilizaram aquele material. A tarefa que apresentou aos alunos foi uma cópia da que ela própria tinha resolvido antes, e, perante a pergunta dos alunos sobre o número de planificações possíveis, disse-lhes apenas que eram muitas. Organizou o trabalho em pequenos grupos a quem foram distribuídos os materiais. Os alunos iniciaram a atividade com grande entusiasmo, e, à medida que iam descobrindo mais planificações, questionavam sobre afinal quantas eram, mas Maria não antecipou a resposta.

Entretanto, um dos grupos chegou às 11 planificações do cubo, pedindo a Maria para verificar. Os outros quatro grupos continuaram o seu trabalho por mais algum tempo, com grande entusiasmo, tendo chegado a 8 ou 9 planificações diferentes, quando a professora deu por terminado o trabalho de grupo. Os alunos compartilharam depois os seus resultados, comparando-os. A professora fez uma síntese final, projetando as onze planificações, que tinha construído quando da planificação da aula.

No relato desta atividade no portefólio, Maria escreveu sobre o entusiasmo dos seus alunos na realização da tarefa, nomeadamente na tentativa de conseguir o máximo de planificações diferentes. Afirma ainda que:

Como professora, este trabalho trouxe-me uma mais-valia nos meus conhecimentos. Por um lado nunca tinha explorado todas as hipóteses de planificações do cubo, antes da sessão de formação em que este tema foi abordado. Por outro, com a preparação e desenvolvimento desta atividade foi possível uma espécie de consolidação sobre as planificações do cubo. A observação do trabalho desenvolvido pelos alunos exige atenção especial para poder identificar possíveis planificações repetidas, o que não deixa de ser um exercício mental também para mim.

Maria enriqueceu o seu conhecimento matemático e didático não apenas pela participação na sessão de formação em grupo, mas, sobretudo quando planificou a aula e trabalhou o assunto com os seus 
alunos, foi aí que o seu conhecimento parece ter sido consolidado. Mais uma vez, o facto de ser uma aula acompanhada terá pesado na decisão de propor a tarefa aos seus alunos.

Outro tópico trabalhado nas sessões de formação em grupo foi, a pretexto de trabalhar as diferentes simetrias de uma figura, o trabalho de construção e identificação dos diferentes tipos de frisos. Este era um tópico do programa oficial desde 1990, mas usualmente apenas era abordado numa perspetiva decorativa. O tema era novo para todas as professoras do grupo de formação, designadamente no que se prendia com a classificação dos diferentes frisos, identificando as transformações geométricas envolvidas e, em especial os diferentes tipos de simetria. A sessão de formação não foi fácil. Através da manipulação de materiais e de muita discussão no grupo as formandas foram identificando as características dos frisos.

No final da sessão, uma das formandas informou que iria trabalhar os frisos na sua turma, pois estava curiosa sobre como reagiriam os alunos. Todas as professoras que lecionavam o $3^{\circ}$ ou o $4^{\circ}$ ano acharam uma boa ideia, funcionaria como uma forma de aprofundarem 0 assunto. Na terceira parte da sessão de formação começaram a pensar na planificação da aula identificando materiais a usar. Maria também selecionou este tópico para a sua terceira aula supervisionada, incluindo a sua planificação, implementação e reflexão no seu portefólio. Utilizou materiais manipuláveis (tiras de cartolina, massinhas, palitos para colocar a cola) para os alunos construírem os seus frisos. Fez uma introdução à tarefa na aula anterior chamando a atenção dos alunos para os frisos que decoravam o casaco de uma das alunas. Reintroduziu o tema na aula acompanhada, lembrando o objetivo da tarefa e distribuindo os materiais pelos grupos. Utilizando triângulos recortados em cartolina (e bostik para colá-los no quadro preto) explicou no quadro o que era friso e pediu a colaboração dos alunos para identificarem diferenças entre os frisos que iam sendo construídos.

Posteriormente, os alunos utilizaram os materiais distribuídos e construíram cada um os seus frisos nas tiras de cartolina. Nesta fase, Maria solicitou a minha colaboração para com ela fazermos a monitorização do trabalho dos alunos. Maria foi, mais uma vez, surpreendida pelo entusiasmo e rapidez dos seus alunos, exprimindo, no decorrer da própria aula, o seguinte desabafo: afinal eles foram muito mais rápidos do que nós na sessão de grupo, tiveram muito mais facilidade. No portefólio registrou que estes adquiriram noções e vocabulário com mais facilidade do que pensava inicialmente:

Curiosamente, toda a turma mostrou, desde o início, muito interesse e vontade em utilizar a linguagem ou os termos novos relacionados com a classificação dos frisos. Parecia terem compreendido facilmente a noção de translação, de reflexão e de meia volta.

Penso que esta tarefa desenvolve o raciocínio, a capacidade de visualização, o sentido espacial e o sentido de estética.

Educação \& Realidade, Porto Alegre, v. 39, n. 4, p. 1051-1069, out./dez. 2014.1065 Disponível em: <http://www.ufrgs.br/edu_realidade> 
Afirmou ainda que o seu envolvimento na preparação da aula fê-la compreender melhor e cimentar as diversas classificações de simetrias e de frisos. O aprofundamento do seu conhecimento matemático e didático foi potenciado pela planificação e lecionação que teve de fazer, o que me leva a afirmar que a formação não teria o mesmo nível de aprofundamento se apenas existisse a sessão de formação em grupo. Mais uma vez, a reação muito positiva dos alunos desenvolveu a auto-confiança de Maria como professora que ensina Matemática.

Como balanço da formação Maria escreveu no portefólio:

Foi uma oportunidade de realizar e aprofundar alguns conhecimentos, colocar dúvidas e dificuldades, ouvir sugestões, trocar ideias, partilhar práticas e experiências... Posso afirmar que o saldo foi muito positivo, permitindo muitos ganhos, a diversos níveis.

Relativamente à minha participação como formadora na sua sala de aula considera-a muito positiva pela segurança que lhe transmitiu, escrevendo: A presença da formadora fez com que eu experimentasse tarefas que de outro modo teria muitas dificuldades e, possivelmente, não avançaria.

Para Maria, a presença da formadora na sala de aula foi um factor que lhe deu segurança para avançar, uma vez que o levar a tarefa para a sala de aula aconteceu porque existiam as sessões de acompanhamento. Este processo permitiu-lhe ir construindo a sua confiança como professora de Matemática no sentido defendido por Graven (2004). Ao planificar as suas aulas, antecipando possíveis resoluções dos alunos para as tarefas propostas, Maria foi consolidando o seu conhecimento matemático e didático. Ao vivenciar a reação dos seus alunos perante tarefas que no grupo de formação tinham sido consideradas complexas, Maria consciencializou que os seus alunos afinal podiam aprender mais Matemática. Confrontada com soluções diferentes ela própria considera que consolidou o seu conhecimento, o que está de acordo com outros estudos (por exemplo, Curi (2005) e Serrazina (1999). Deste modo, Maria compreendeu que podia desenvolver um ensino mais proficiente da Matemática (Kilpatrick; Swafford; Findell, 2001), sobretudo visível ao fim de dois anos de formação, o que está de acordo com o afirmado por Curi e Pires (2008) relativamente à necessidade de tempo para a formação.

\section{Considerações Finais}

A formação de professores que ensinam Matemática nos primeiros anos é uma tarefa complexa e desafiante para todos aqueles que nela estão envolvidos. A experiência obtida com o PFCM em Portugal mostra que se trata de um processo que tem de ser continuado no tempo e desenvolvido a partir das práticas de sala de aula. Mudar práticas implica alteração de conceções e crenças sobre o ensinar e aprender

1066 Educação \& Realidade, Porto Alegre, v. 39, n. 4, p. 1051-1069, out./dez. 2014 Disponível em: <http://www.ufrgs.br/edu_realidade> 
Matemática que muitas vezes estão muito sedimentadas, havendo uma forte resistência à sua alteração (Curi, 2005; Serrazina, 1999). Acresce que, no caso dos professores dos anos iniciais, coexiste ainda uma falta de confiança como professores de Matemática que pode ser ultrapassada através da vivência de experiências concretas na sala de aula interligadas com uma melhoria do conhecimento matemático, didático e curricular. No PFCM, a interligação entre os dois tipos de sessões e a sua estreita relação com a prática de sala de aula, e ainda a presença do formador na sala de aula e o seu papel ativo na reflexão pós-aula merecem destaque. O modo como foram organizadas as sessões de formação em grupo, com os três momentos: reflexão das aulas anteriores, aprofundamento de tópicos matemáticos e/ou didáticos e planificação das aulas seguintes, parece adequado aos objetivos da formação.

Confrontando o caso da Maria com os contributos teóricos apresentados pode afirmar-se que um programa de formação continuada, com as características do PFCM, desenvolvido num ambiente de colaboração entre formandos e destes com o formador, prolongado no tempo, com uma forte preocupação com o aprofundamento do conhecimento matemático do professor, não o desligando do seu conhecimento didático e curricular, onde as práticas letivas são simultaneamente ponto de partida e de chegada, desenvolve a autoconfiança dos professores quer na sua capacidade de aprender Matemática quer em ensiná-la aos seus alunos.

O espaço de sala de aula é um espaço fundamental para o êxito da formação, associado à análise dos trabalhos dos alunos e à reflexão do professor quer individualmente quer com os seus pares (Serrazina, 2013). O envolvimento dos professores em tarefas exploratórias (Ponte, 2005), que posteriormente podem adaptar e propor aos seus alunos parece ser um bom ponto de partida.

Em resumo, os dados disponíveis, permitem-nos afirmar que a formação alargada no tempo, desenvolvida a partir das práticas de sala de aula e envolvendo a reflexão sobre essas práticas, o aprofundamento do conhecimento matemático, didático e curricular do professor, aumenta a confiança do professor como professor que ensina Matemática e tem repercussões positivas na melhoria da aprendizagem dos alunos (Serrazina, 2013).

Recebido em 25 de março de 2014 Aprovado em 23 de julho de 2014

\section{Notas}

1 O PFCM foi alargado a partir de 2006/07 também aos professores do $2^{\circ}$ ciclo (1011 anos), mas este artigo centra-se apenas no $1^{\circ}$ ciclo do ensino básico (6-9 anos).

2 No $2^{\circ}$ ano de formação deixaram o grupo duas formandas, tendo-o integrado duas outras que tinham realizado o $1 .^{\circ}$ ano de formação no ano anterior (2005/06).

Educação \& Realidade, Porto Alegre, v. 39, n. 4, p. 1051-1069, out./dez. 2014.1067 Disponível em: <http://www.ufrgs.br/edu_realidade> 


\section{Referências}

ALARCÃO, Isabel. Reflexão Crítica sobre o Pensamento de D. Schon e os Programas de Formação de Professores. In: ALARCÃO, Isabel (Org.). Formação Reflexiva de Professores, Estratégias de Supervisão. Porto: Porto Editora, 1996. P. 9-39.

BALL, Deborah. Research on Teaching Mathematics: making the subject-matter knowledge part of the equation. In: BROPHY, Jere (Org.). Teachers' Knowledge of Subject Matter as it Relates to their Teaching Practice. Greenwich: JAI Press. 1991. P. 11-48.

BALL, Deborah; BASS, Hyman. Toward a Practice-Based Theory of Mathematical Knowledge for Teaching. In: DAVIS, Brent; SIMMT, Elaine (Org.). Proceedings of the 2002 Annual Meeting of the Canadian Mathematics education Study Group. Edmonton, AB: CMESG/GCEDM, 2003. P. 3-14.

BALL, Deborah; THAMES, Mark; PHELPS, Geoffrey. Articulating Domains of Mathematical Knowledge of Teaching. Paper Presented at the American Educational Research Conference, Montreal, Québec, 2005.

BALL, Deborah; THAMES, Mark H.; PHELPS, Geoffrey. Content Knowledge for Teaching: what makes it special? Journal of Teacher Education, v. 59, n. 5, nov./ dez, p. 389-407, 2008.

BESWICK, Kim; ASHAM, Di CALLINGHAM Rosemary; MCBAIN, David. Teachers' and Pre-service Teachers' Confidence to Teach Primary School Mathematics. In: PROCEEDINGS OF THE 2011 AUSTRALIAN ASSOCIATION FOR RESEARCH IN EDUCATION CONFERENCE, Hobart, Tasmânia, 27 nov./1 dez. 2011. Hobart, Austrália. P. 1-10.

CURI, Edda. A Matemática e os Professores dos Anos Iniciais. São Paulo: Musa Editora, 2005.

CURI, Edda; PIRES; Célia Maria Carolino. Pesquisas sobre a Formação do Professor que Ensina Matemática por Grupos de Pesquisa de Instituições Paulistanas. Educação Matemática Pesquisa, São Paulo, PUC/SP, 2008, n. 10, p. 151-189, 2008.

FIORENTINI, Dario; NACARATO, Adair M.; PINTO, Renata A. Saberes da Experiência Docente em Matemática e Educação Continuada. Quadrante, Lisboa, Associação de Professores de Matemática, n. 8, p. 33-59, 1999.

GRAVEN, Mellony. Investigating Mathematics Teacher Learning within an in-service Community of Practice: the centrality of confidence. Educational Studies in Mathematics, Dordrecht, Springer, p. 2, 57, 177-211, 2004.

JAWORSKI, Barbara. The Professional Development of Teachers - the Potential of Critical Reflection. British Journal of In-Service Education, Abingdon, Oxon, Taylor \& Francis, v. 19, p. 37-42, 1993.

KILPATRICK, Jeremy; SWAFFORD, Jane; FINDELL, Bradford (Org.). Adding it Up. Washington, DC: National Academy Press, 2001.

MARTINS, Cristina. O Desenvolvimento Profissional de Professores do $1^{\circ} \mathrm{Ci}$ clo do Ensino Básico: contributos da participação num programa de formação continua em matemática. 606 f. 2011. Tese (Doutorado em Educação) - Universidade de Lisboa, 2011.

NACARATO, Adair M.; MENGALI, Brenda L. S.; PASSOS, Carmen Lúcia Brancaglion. A Matemática nos anos Iniciais do Ensino Fundamental. Belo Horizonte: Autêntica, 2009.

1068 Educação \& Realidade, Porto Alegre, v. 39, n. 4, p. 1051-1069, out./dez. 2014. Disponível em: <http://www.ufrgs.br/edu_realidade> 
OCDE. Learning for Tomorrow World - first results of PISA 2003. 2004. Disponível em: <http://www.oecd.org/pisa/pisaproducts/pisa2003/learningfortomorrowsworldfirstresultsfrompisa2003.htm>. Acesso em: 30 out. 2013.

PONTE, João Pedro. Gestão Curricular em Matemática. In: GTI (Org.). O Professor e o Desenvolvimento Curricular. Lisboa: APM, 2005. P. 11-34.

PORTUGAL. Ministério da Educação (ME). Programa de Matemática do Ensino Básico. Lisboa; Ministério da Educação, DGIDC, 2007.

SCHON, Donald. The Reflective Practioner: how profissionals think in action. New York: Basic Books, 1983.

SERRAZINA, Lurdes. Reflexão, Conhecimento e Práticas Lectivas em Matemática num Contexto de Reforma Curricular no $1^{\circ}$ Ciclo. Quadrante, Lisboa, Associação de Professores de Matemática, p. 8, 139-167, 1999.

SERRAZINA, Maria de Lurdes. O Programa de Formação Contínua em Matemática para Professores do $1^{\circ}$ e $2^{\circ}$ Ciclo do Ensino Básico: balanço possível. Interacções, Santarém, Escola Superior de Educação, n. 12, p. 4-22, 2009.

SERRAZINA, Maria de Lurdes. O Programa de Formação Contínua em Matemática para Professores do $1^{\circ}$ Ciclo e a Melhoria do Ensino da Matemática. Revista da Investigação às Práticas, Lisboa, Escola Superior de Educação, CIED, n. 3, v. 2, p. 75-97, set. 2013.

SERRAZINA, Lurdes; CANAVARRO, Paula; GUERREIRO, António; ROCHA, Isabel; PORTELA, José; SARAMAGO, Maria João. Programa de Formação Contínua em Matemática para Professores do $1^{\circ}$ Ciclo. 2005. Disponível em: <http://www. dgidc.min-edu.pt/outrosprojetos/index.php?s=directorio\&pid=31>. Acesso em: 30 out. 2012.

SHULMAN, Leo. Those who Understand Knowledge Growth in Teaching. Educational Researcher, Washington, American Educational Research Association, v. 15, n. 2, p. 4-14, 1986.

STEIN, Mary Kay; REMILLARD, J.; SMITH, Margaret Schan. How Curriculum Influences Student Learning. In: LESTER, Frank (Org.). Second Handbook of Research on Mathematic Teaching and Learning: a project of the national council of teachers of mathematics. Charlotte: Information Age Publishing, v. II, p. 319-369, 2007.

STEIN, Mary Kay; SMITH, Margaret Shan. Mathematical Tasks as a Framework for Reflection: from research to practice. Mathematics Teaching in the Middle Schoool, Reston, Va, National Council of Teachers of Mathematics, v. 3, n. 4, 1998. P. 268-275.

VIEIRA, Flávia. Uma Prática Reflexiva de Formação de Professores. Rio Tinto: Edições ASA, 1993.

Maria de Lurdes Serrazina é professora coordenadora (aposentada) da Escola Superior de Educação do Instituto Politécnico de Lisboa, Membro da Unidade de Investigação em Educação e Desenvolvimento (UIDEF) do Instituto de Educação da Universidade de Lisboa, Professora Associada Convidada (aposentada) do Instituto de Educação da Universidade de Lisboa, PhD em Educação Matemática pela Universidade de Londres (UK) (1998). Foi coordenadora do Programa Nacional de Formação Contínua em Matemática de 2005 a 2011.

E-mail: lurdess@eselx.ipl.pt

Educação \& Realidade, Porto Alegre, v. 39, n. 4, p. 1051-1069, out./dez. 2014.1069

Disponível em: <http://www.ufrgs.br/edu_realidade> 